\title{
Cervical Leiomyoma
}

National Cancer Institute

\section{Source}

National Cancer Institute. Cervical Leiomyoma. NCI Thesaurus. Code C128046.

An uncommon benign smooth muscle neoplasm that arises from the cervix. 